\title{
ROLLING INTO THE FUTURE, LONG ROLLING CONTROL SYSTEM UTILIZING THE CHANGING TRENDS IN TECHNOLOGY AND DIGITALIZATION *
}

Paul Riches ${ }^{1}$

\begin{abstract}
Today's steel producers face the dual challenge of ensuring on-time delivery and ever demanding product requirements, while also running a lean operation. Every day the management of a long rolling plant requires continuous optimization of both operating and business practices. Imagine a long rolling facility, where individual pieces of equipment communicate with each other, where sensor information can be used not only for control purposes but to also monitor the condition of the equipment, where models are used to verify the process is within working limits and the equipment raises alerts to operators when it requires maintenance! Utilizing the ongoing evolution in technology though data collection, communication, internet of things, control techniques and smart sensors, there is now more information available than ever before. The collection and analysis of this information will both advance control and monitoring of plant performance; revolutionizing long rolling mill plants worldwide and optimizing the entire value chain, along with improved and more flexible production.

Keywords: Digitalization; Industry 4.0; Smart Sensors; Product Quality; Rolling Process; Rolling Flexibility; Safety; Operating Costs; Maintenance costs; Operation setup; Operator Intervention; Product Storage; Logistics; Long Rolling; Key Performance Indicators (KPI's); Expert System; Mill Management; Production Data Analysis; Roll Shop Management; Pass Schedule Handling; Delays Classification; Long Rolling Mill Production Scheduling.
\end{abstract}

1 Engineer, Sales Director, EA Long Rolling/PT USA LLC, Worcester, MA, USA. 


\section{INTRODUCTION}

"You cannot manage what you do not measure" - to reach the goals for future market requirements it is imperative to fully understand the operation of a long rolling facility. With the ongoing technological evolution, it is ever easier to collect, manage and collate data at all levels within the mill, to understand and improve processes, operations and maintenance requirements.

New concepts are being developed to improve the operational management of the critical areas within a long rolling mill. Using existing installed technology, combined with smart sensors such as non-contact measurement devices, vision systems, intelligent temperature measurement, RFID for product tracking, additional real time data will become accessible. Utilizing the powerful computational and network systems now available, this data can be collected, collated, analysed and reported; allowing operators to make rapid, educated decisions on the mill floor and providing a higher level of automation within long rolling mills.

These concepts alone will lead to improvements in Product Quality, Rolling Process, Rolling Flexibility, Operating Costs, Maintenance costs, Operation setup, Operator Intervention, Product Storage and Logistics

With the growth in plant digitalization, the increase in data available for collection, utilization, analysis and distribution, along with intelligent models (or process based systems) used for production planning, product quality, mill and equipment maintenance, a revolution in long rolling mill control systems is occurring.

\section{DISCUSSION}

Primetals Technologies continuously develops new technological functions and packages for long rolling to improve quality, mill flexibility, mill efficiency and increase overall productivity. These packages are based on the latest technologies, business trends and close cooperation with key customers, to understand and meet the challenges of customers, in order to provide tools to support customers for the growth in technology and requirements for the future long rolling plant requirements.

It should be understood that Industry 4.0 IS NOT a PRODUCT, but a group of technological, process and maintenance packages to support the transition of a long rolling plant to meet the future requirements of plant digitalization. 


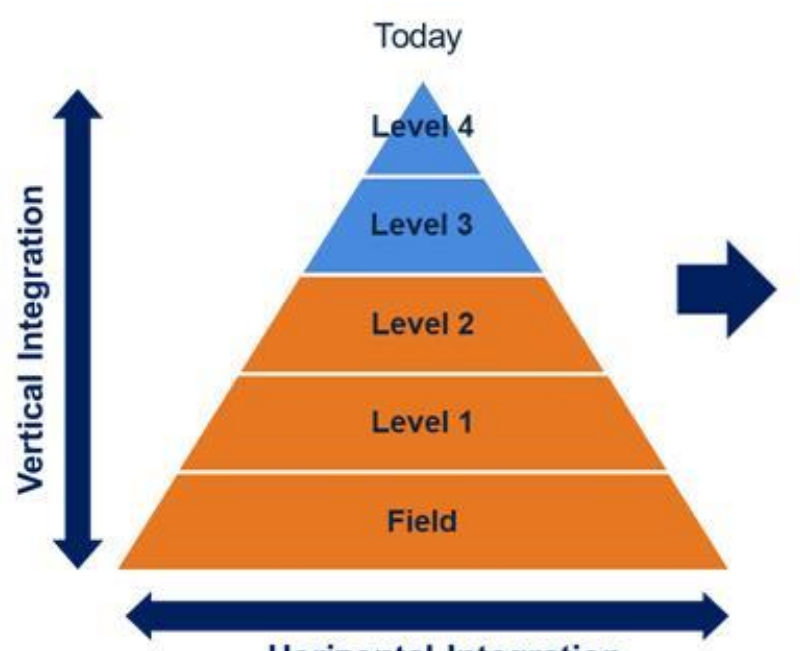

Horizontal Integration

Internet of Things
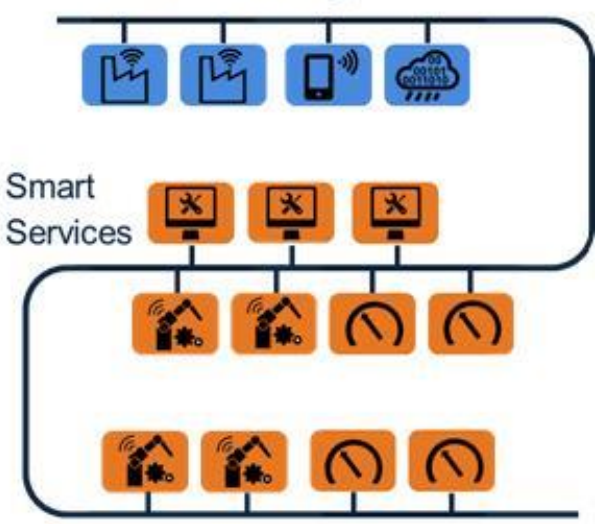

Cyber-Physical Systems

Figure 1. Mill control system hierarchy today vs tomorrow.

Today we have the traditional horizontal and vertical integration of the mill control and supervisory systems, as can be seen in Fig. 1. With the change in technology we will, in future, be able to communicate on one plane, allowing long rolling customers to collect data and communicate to all sensors, machines and processors within a plant. The internet of things (loT) becomes a major pathway for sensors and systems to collect and communicate data.

Primetals Technologies have developed packages to support the future trend to digitalize long rolling plants; these packages are designed in such a manner that equipment can be added to existing plants, in a phased approach, to help support the long term future requirements of long rolling customers (see Fig. 2).

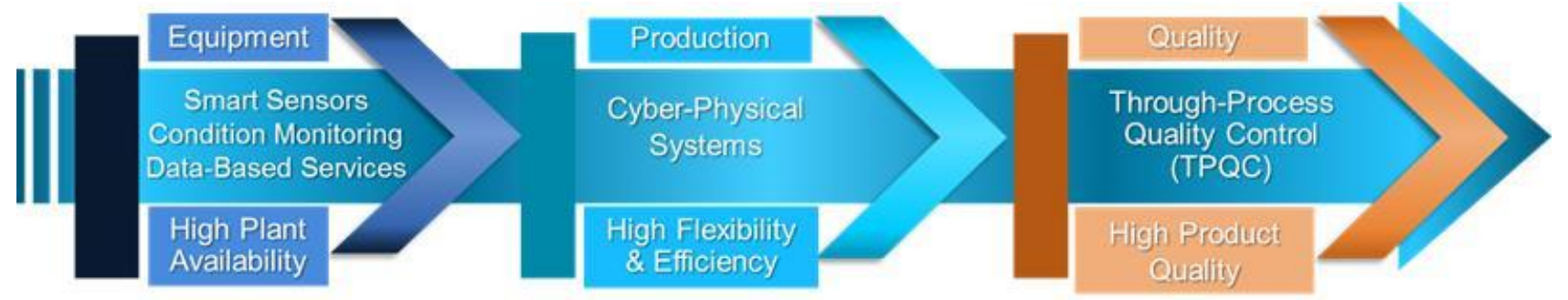

Figure 2. Approach to reach future requirements of long rolling customers.

Future requirements will dictate the following within a long rolling plant;

Equipment: Intelligence (both process and maintenance), High plant availability

Production: High Flexibility, High Efficiency

Quality:

High Product Quality, Product Flexibility,

Understanding the requirements of the equipment, processes and control within a long rolling mill has allowed Primetals Technologies to design and implement packages to meet the future demands of the industry.

\section{Equipment}


Every customer is aiming for high plant availability. With the addition data from devices such as smart sensors, advances in predictive maintenance and condition monitoring systems, this goal can be achieved. By adding these concepts and utilizing the vast amount of data now available, intelligence can be added for each piece of equipment.

Imagine Stand \#1 informing stand \#2 what is happening to the product, and what is required from stand \#2 based on the rolling condition of stand \#1 - or the roughing mill communicating with the intermediate mill! Although this seems highly visionary today, based on the level of control within a long rolling mill, this type of control is coming.

A good example of this is an image sensor (smart sensor) added between two stands. This can provide both actual real-time speed and the product dimensions, improving not only the process, but also mill safety, by eliminating the necessity for operators to take actual physical measurements of the product. This single, simple illustration shows the true benefits to customers of developing such sensors; a small, but important piece of meeting customers' future requirements. Fig. 3 shows an example of an in-line product dimension measurement.

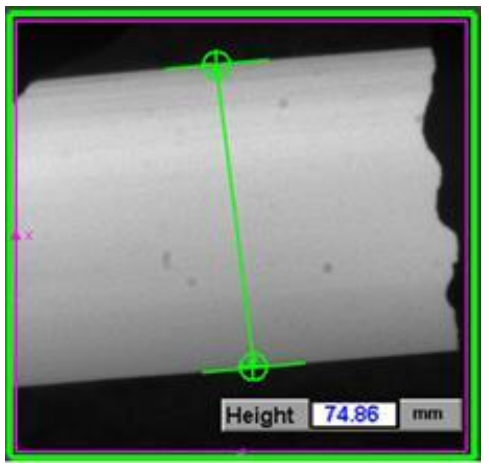

Figure 3. HMl view of product height being measured dynamically in a roughing mill. 
Table 1 below shows the benefits to customers of adding small technological packages into a wire rod mill in order to enhance the overall control of the rolling process:-

\begin{tabular}{|c|c|c|c|c|c|c|c|}
\hline FURNACE & $\mathrm{RM}$ & IM & $\mathrm{FM}$ & $\begin{array}{l}\text { STELMOR } \\
\text { COOLING }\end{array}$ & $\begin{array}{c}\text { COIL } \\
\text { HANDLING }\end{array}$ & RESULT & $\begin{array}{l}\text { Pre-cond } \\
\text { Sensor }\end{array}$ \\
\hline & $\begin{array}{c}\text { Height and } \\
\text { width } \\
\text { measurement }\end{array}$ & $\begin{array}{l}\text { Height and } \\
\text { width } \\
\text { measurement }\end{array}$ & & & & $\begin{array}{l}\text { STOCK CONTROL IN } \\
\text { RVILL / IMILL } \\
\text { CONSITANCY IN MTC AND } \\
\text { MILL SETUP } \\
\text { PREDICTIVE CDOUNG }\end{array}$ & $\begin{array}{l}\text { Vision / Non } \\
\text { Contact Laser }\end{array}$ \\
\hline & $\begin{array}{l}\text { Praduct Speed } \\
\vdots \\
\vdots\end{array}$ & $\begin{array}{l}\text { Product Speed } \\
\text { measurement }\end{array}$ & $\begin{array}{l}\text { Product Speed } \\
\text { measurement }\end{array}$ & & & $\begin{array}{l}\text { YIELD IMPROVEMENT } \\
\text { [SHEARR CONTROL] } \\
\text { MASS FIOWW CALC } \\
\text { MTC. BETWEEN FINISHING } \\
\text { BLOCKS (IMPROVE } \\
\text { PRODUCT TOLERANCE } \\
\text { DPNAMIC NILL SET UP } \\
\text { PINCH ROLL CONTROL } \\
\text { LAYING HEAD CONTROL } \\
\end{array}$ & $\begin{array}{l}\text { Non Contsct } \\
\text { Laser }\end{array}$ \\
\hline & $\vdots$ & & $\begin{array}{l}\text { Muto toil } \\
\text { Position }\end{array}$ & & & INPRONE QUALITY & Vision System \\
\hline & $\vdots$ & & & $\begin{array}{l}\text { Temperature } \\
\text { Control }\end{array}$ & & $\begin{array}{l}\text { IVPRONE QUALITY, } \\
\text { OEFINE PRODUCT } \\
\text { TRANSFORMATION POINT }\end{array}$ & Thermal scan \\
\hline & : & & & & $\begin{array}{l}\text { Auto coil shispe } \\
\text { control }\end{array}$ & $\begin{array}{l}\text { COIL PACKNGE } \\
\text { IMPROVFNENT }\end{array}$ & Vsion \\
\hline & : & & & & Intelli Coil & $\begin{array}{l}\text { LOGISTICS IMPROVENENT } \\
\text { IN COIL YARD }\end{array}$ & Wireless TAG \\
\hline
\end{tabular}

Table 1. Benefits of technological packages to mill operations.

\section{Smart sensors for Long Rolling}

A 'smart' sensor is defined as that which is able to measure / monitor the process with a degree of 'internal processing', or 'intelligence'. It provides information that up until now has often been unavailable; particularly in real-time. Smart sensors either directly measure physical values, or use existing measurements, to indirectly calculate additional information. These are the enablers for the implementation of advanced automatic functions, process models, as well as condition monitoring. Such devices provide continuous information on state of the processes, enabling ever more sophisticated monitoring and control of the entire plant.

Installing packages that have been developed around smart sensors provides new and improved process metrics, leading to a more intelligent rolling process. By reducing mill setup time and implementing condition monitoring and predictive maintenance, overall plant operation can be significantly improved - seen by an increase in quality, yield and flexibility.

Fig. 4 lists some of the smart sensors available and their application in the long rolling process. 


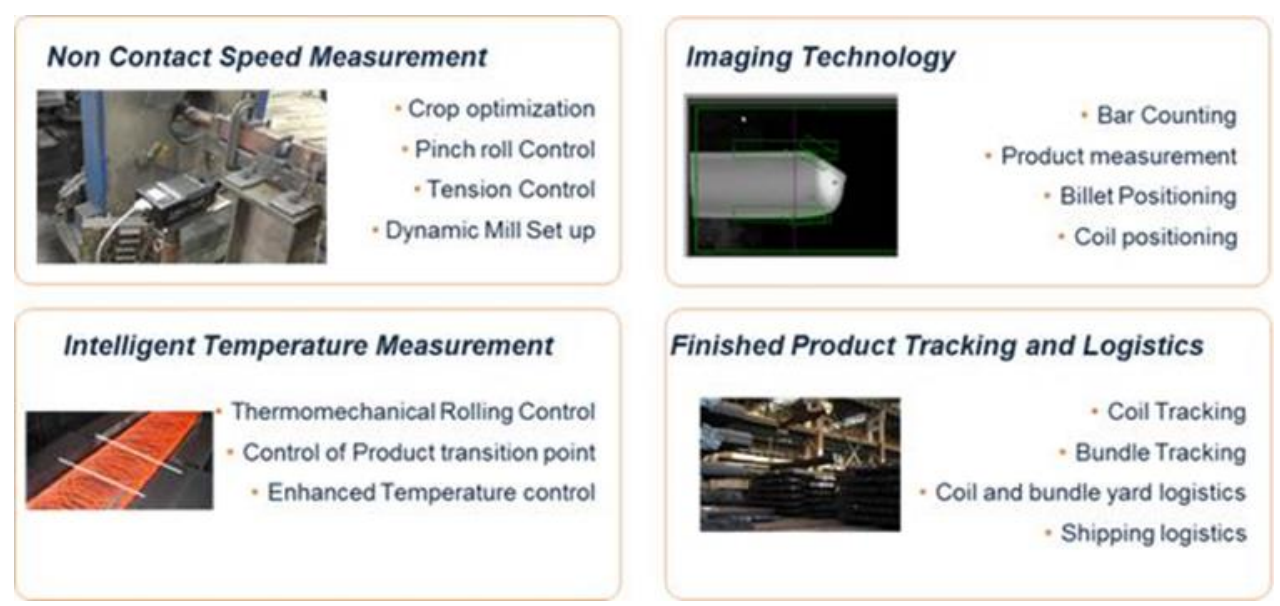

Figure 4. A sample of SMART sensors developed for long rolling applications

\section{Production}

Every customer is aiming for flexibility and high efficiency in their production cycle. As discussed earlier, with advancements in software and powerful network systems, we now have the tools to collect, sort and analyze large amounts of data. Utilizing these tools in Cyber Physical Systems (CPS) allows the production performance to be monitored, analyzed and measured against Key Performance Indicators (KPIs) to ensure the planned production is being followed.

A CPS is a virtual model of the REAL PHYSICAL plant or process and is used to verify the consequences of changing the plant conditions. The model is formed from integrations of computation, networking, and physical processes (see Fig. 5). Embedded computers and networks monitor and control the physical processes with feedback loops, where physical processes affect computations and vice versa.

CPS Is the future of the Process automation. A CPS can be a model of an individual process; such as cooling model to calculate the temperature equalization in a rail mill, water box set up in a conventional rod or bar mil, or mill set up and the roll pass calculations.

By utilizing CPS in the future, mill operators and supervisors will be able to understand the effects of a change in set up of a certain process or piece of equipment BEFORE the change is made. 


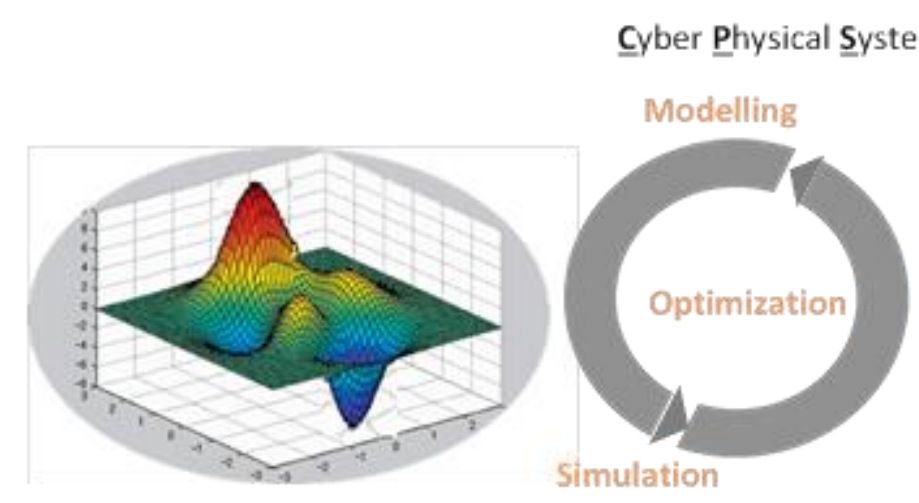

VIRTUAL PLANT

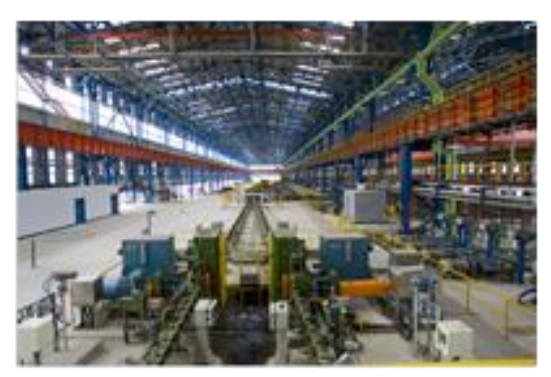

REAL (physical) PLANT

Simulation allows Pre-visualization what will happen in the Real Plant

Figure 5. Cyber Physical System

\section{Quality - Through Process Quality Control, Through Process Optimization (TPOpt)}

TPOpt provides knowhow based identification of non-conformities, determines the related root cause and provides corrective and compensational actions throughout the entire production chain. It effectively helps to achieve the intended product specifications and support quality management.

This system integrates the quality knowhow of a product with the real-time process. A rule-based system checks the resultant data at each process event. A decision is made based on these rubrics as to whether the product quality is within the defined limits. The system then determines corrective dynamic adjustments to the processes both upstream and downstream, relative to the event position. This will consequently enhance the overall product quality by both preventing further quality issues from occurring and rectifying those detected. Fig. 6 shows an example of the rules-based system. This is a dynamic quality control system, updating the process requirements of the product as it is being made. Although Fig. 6 shows only a long rolling plant section, Primetals Technologies' TPQC system monitors quality throughout the entire process from the liquid phase to the finished product. 


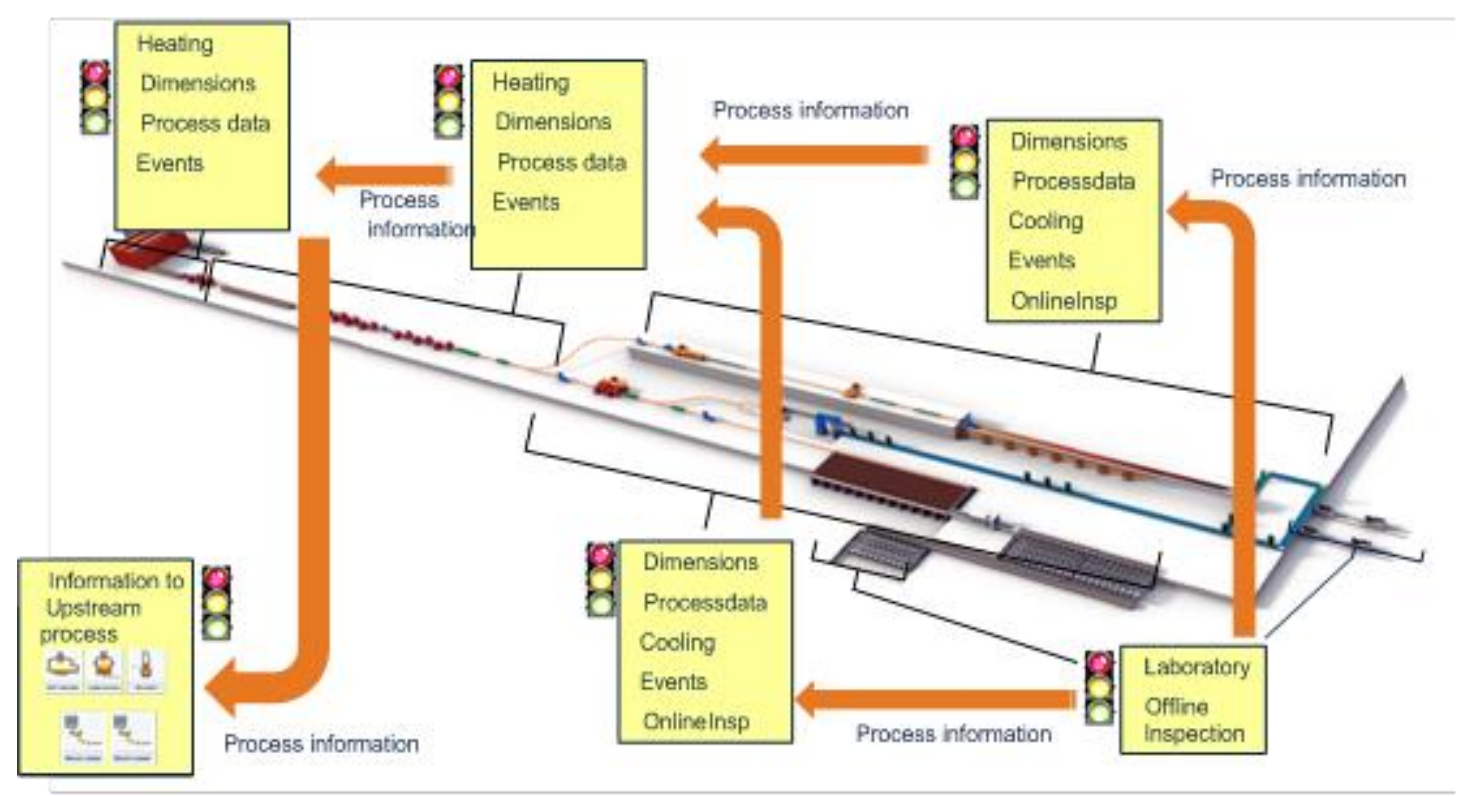

Process information collected for products, heats - ufiized for next rolling campaign

Figure 6. Rules-based Through Process Quality Control system

\section{Process Expert}

Primetals Technologies Process Expert monitors and collects data from the raw material stage through to the finished product. Its domain extends from the enterprise resource planning (ERP), through Manufacturing Execution Systems (MES), to control systems and right down to level 1 devices. The system delivers valuable mill reports to the operator staff and management so they can easily assess a plant's performance and optimize production. Defined Key Performance Indicators (KPI's) help to assess a plants performance; the system is not limited to one plant but can enable plant to plant performance at corporate level. 


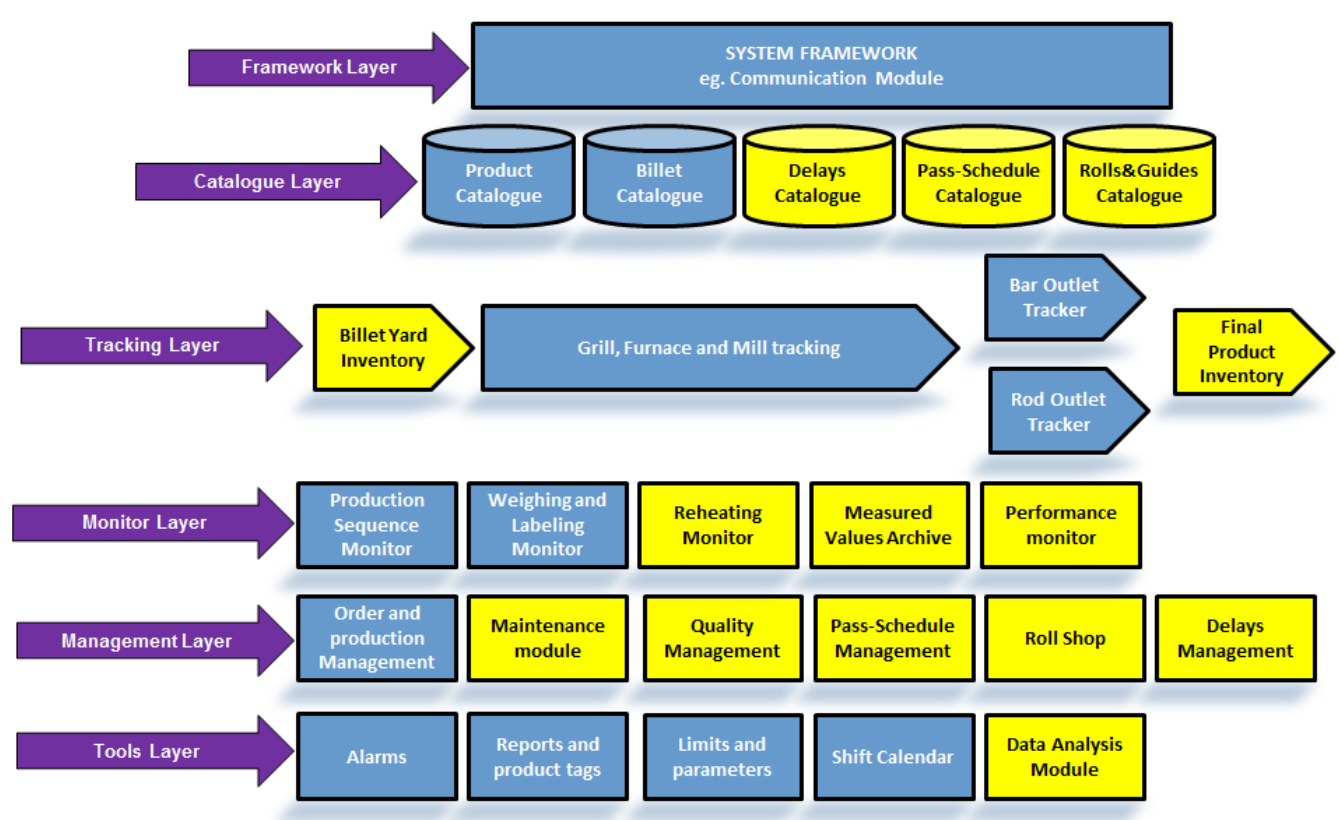

Figure 7. Primetals Process Expert modules overview

The basic technological modules, based on extensive experience in the long rolling industry, include:

- Production sequencing

- Heat data management

- Raw material assignment

- Automatic mill setup data management and control

- Material tracking

- Data processing/archiving

- Plant monitoring

- Pass Scheduling

- Weighing and tagging

- Analysis and report manager

- Delay management

- Online system help

- User-friendly integrated HMI

- Definition of KPIs

- Genealogy module

- QUALITY on line monitor

Optional modules of Primetals Process Expert:

- Interface to MES - Manufacturing Execution System (L3) and other IT systems

- Production program optimization

- Roll and guide management

- Melt shop interface

- Maintenance tracking and guide manager

- Offline sample \& laboratory interface generation of QA certificates

- Billets and final product yards inventory 


\section{Condition Monitoring}

Primetals Technologies utilizes mechanical and electrical knowledge of the equipment and the process to monitor the condition of the equipment - not only in the rolling mill, but also upstream and downstream components, thus guaranteeing all elements contributing to plant operation are monitored. This ensures that planned downtime and shutdowns are optimized; to be as minimal and efficient as possible, throughout the complete process. Fig. 8 shows an example of a comprehensive condition monitoring system.

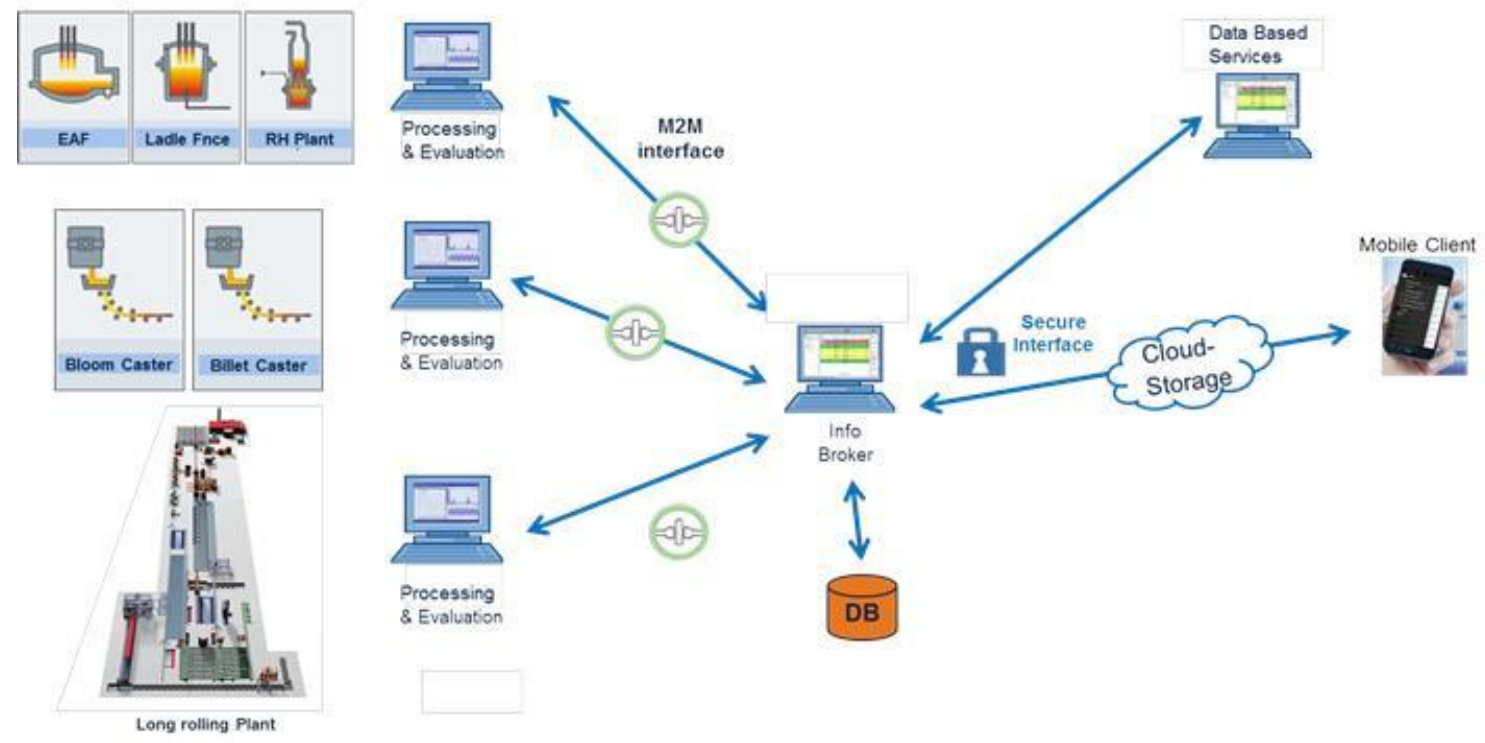

Figure 8. Condition Monitoring System

Equipment condition data is acquired at each plant level, then processed and evaluated against known operating standards and reported back at the plant level. Utilizing the equipment knowledge within Primetals Technologies, the system can process the data and alert when maintenance is required. By knowing the status of the equipment throughout the full process line, downtime for maintenance can be optimized at the plant level.

Work instructions for maintenance personnel (including any spares required) will be produced automatically, along with any additional information required for the maintenance project - including those obtained through 3-D interactive models on tablets; further minimizing downtime. 


\section{SUMMARY}

Along with the systems described in this paper, Primetals Technologies is also working on improved automated equipment and robotics to help increase productivity and reduce downtime. From an equipment standpoint, the goal is to replace the fluids-driven equipment with electrical and servo-controlled devices that offer more information on both the equipment and feedback of the process itself. An example of this is the patented Morgan Intelligent Pinch Roll, where the pinch control of the roll, originally done pneumatically, has been replaced by electric servo motor control. This provides high speed, accurate and repeatable control and feedback of the pinch roll pressure and opening throughout the different stages of rolling process.

Primetals Technologies is working on robotic applications with the goal of replacing heavy, dangerous manual maintenance functions and repetitive operations - for instance; laying head pipe change, roll change, shear blade change. Robotic control systems will be supported by fully-automated mechatronic solutions, allowing operators more time to focus on the essential tasks of the process and the plant.

Table 2 below represents the true digitalization of long rolling, using a wire rod mill example. The same results can be gained for any long rolling facility. By developing systems that can be introduced into long rolling mills in a phased approach, it allows customers to utilize the tools provided to ensure their target for digitalization can be achieved in a cost effective manner.

\begin{tabular}{|c|c|c|c|c|c|c|c|c|}
\hline \multirow{3}{*}{$\begin{array}{c}\text { Through Process } \\
\text { Control }\end{array}$} & \multicolumn{8}{|c|}{ Digitalization of a Long Rolling Mill (WRM) } \\
\hline & FURNACE & RM & IM & FM & $\begin{array}{l}\text { STELMOR } \\
\text { COOLING }\end{array}$ & $\begin{array}{c}\text { COIL } \\
\text { HANDLING }\end{array}$ & RESULT & $\begin{array}{l}\text { Pre-cond } \\
\text { Sensor }\end{array}$ \\
\hline & \multicolumn{6}{|c|}{ THROUGH PROCESS QUALITY CONTROL } & $\begin{array}{l}\text { IMPROVED PRODUCT, } \\
\text { DYNAMIC SCHEDULING }\end{array}$ & \\
\hline \multirow{6}{*}{ 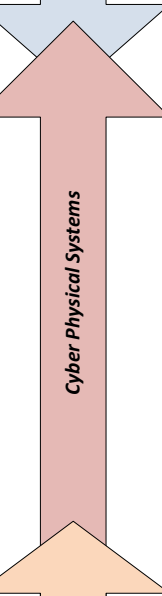 } & & $\begin{array}{l}\text { Height and } \\
\text { width } \\
\text { measurement }\end{array}$ & $\begin{array}{l}\text { Height and } \\
\text { width } \\
\text { measurement }\end{array}$ & & & & $\begin{array}{c}\text { STOCK CONTROL IN } \\
\text { RMILL / IMILL } \\
\text { CONSITANCY IN MTC AND } \\
\text { MILL SETUP } \\
\text { PREDICTIVE COOLING }\end{array}$ & $\begin{array}{l}\text { Vision / Non } \\
\text { Contact Laser }\end{array}$ \\
\hline & & $\begin{array}{l}\text { Product Speed } \\
\text { measurement }\end{array}$ & $\begin{array}{l}\text { Product Speed } \\
\text { measurement }\end{array}$ & $\begin{array}{l}\text { Product Speed } \\
\text { measurement }\end{array}$ & & & $\begin{array}{c}\text { YIELD IMPROVEMENT } \\
\text { (SHEAR CONTROL) } \\
\text { MASS FLOW CALC } \\
\text { MTC BETWEEN FINISHING } \\
\text { BLOCKS (IMPROVE } \\
\text { PRODUCT TOLERANCE } \\
\text { DYNAMIC MILL SET UP } \\
\text { PINCH ROLL CONTROL } \\
\text { LAYING HEAD CONTROLL }\end{array}$ & $\begin{array}{l}\text { Non Contact } \\
\text { Laser }\end{array}$ \\
\hline & & & & $\begin{array}{l}\text { Auto coil } \\
\text { Position }\end{array}$ & & & IMPROVE QUALITY & Vision System \\
\hline & & & & & $\begin{array}{c}\text { Temperature } \\
\text { Control }\end{array}$ & & $\begin{array}{l}\text { IMPROVE QUALITY, } \\
\text { DEFINE PRODUCT } \\
\text { TRANSFORMATION POINT }\end{array}$ & Thermal scan \\
\hline & & & & & & $\begin{array}{l}\text { Auto coil shape } \\
\text { control }\end{array}$ & $\begin{array}{l}\text { COIL PACKAGE } \\
\text { IMPROVEMENT }\end{array}$ & Vision \\
\hline & & & & & & Intelli Coil & $\begin{array}{l}\text { LOGISTICS IMPROVEMENT } \\
\text { IN COIL YARD }\end{array}$ & Wireless TAG \\
\hline Maintenance & \multicolumn{6}{|c|}{ CONDITION MONITORING (CMS) } & $\begin{array}{l}\text { INCREASED EFFICIENCY OF } \\
\text { MAINTENANCE AND } \\
\text { REDUCED DOWNTIME }\end{array}$ & \\
\hline
\end{tabular}

Table 2. Long rolling mill digitalization. 


\section{BENEFITS}

The benefits of these systems are numerous. They can be aligned to meet customers' short term goals, be an integral part of a long term strategy for process digitalization, and help meet the challenges that long rolling plants will face in the future to achieve the ever demanding requirements of the market. With the evolution of technology, implementing the systems developed and now available, the following benefits will be achieved realized:

- Increase operator safety - Smart sensors

- Minimize monotonous, repetitive, dangerous and heavy work - Robotics

- Auto mill set up - CPS, Smart sensors

- Self-learning systems - CPS

- Dynamic production sequencing and scheduling - CPS

- Auto logistic systems - Smart sensors

- Equipment knowhow - Condition monitoring, Smart sensors

- Predictive maintenance - Condition monitoring

- Smart operators - Smart Sensors, CPS, TPQC

- Process monitoring and production tracking - Smart sensors, TPQC

- Continuous quality monitoring - TPQC

- Quality knowhow - TPQC

- Quality certification - TPQC

- Consistent, synchronized storage of all product, process and plant data for analysis, control and tracking traceability - All systems

- Automatic detection and classification of process deviations and defects TPQC

- Reduced manual product inspection, rework overhead and avoidance of quality downgrades - TPQC

- Reduction of the "human factor" - All systems

- Knowhow documentation in a rule-based expert system - TPQC, Condition monitoring

\section{CONCLUSION}

The Advantages of the Primetals Technologies approach to digitalization (Industry 4.0) are:

- The solution is not "OFF THE SHELF", but tailored to each individual mill's requirement

- Technological packages that can be introduced in phases to existing and new facilities with IMMEDIATE customer value and return of investment

- Developments in all directions, - Quality, Productivity and Flexibility

- Each long rolling customer must, with the assistance of Primetals Technologies, define their own particular implementation strategy for Industry 4.0 readiness

- Primetals Technologies will actively assist long rolling customers in the digital transformation of their production plants with portfolio elements and services 
This approach to the digitalization of the long rolling industry will enable customers to set both their short and long term goals in a phased approach. Strategically planned investment to meet the future requirements of the industry will allow optimized implementation of these ever evolving technologies and harness the full power Industry 4.0. 